\title{
The Effectiveness of Writing Across the Curriculum in a Baccalaureate Social Work Program: Students' Perceptions
}

\author{
Naelys Luna \\ E. Gail Horton \\ Jeffrey R. Galin
}

\begin{abstract}
Effective social work practice requires strong writing and communication skills; however, social work students often experience difficulties performing academically at expected levels. This article presents findings from a student survey that was collected for two years to assess perceptions of the effectiveness of Writing Across the Curriculum (WAC) strategies on writing skills and social work knowledge acquisition in an introductory social work class that is taught every semester at a school of social work located in southeastern Florida. Students reported that WAC strategies substantially improved their abilities to write in the discipline and learn course content. Based on our findings, it is recommended that schools of social work infuse WAC throughout their curriculum, a process that requires cross curricular collaboration, intra-departmental support, and faculty commitment to course development and implementation.
\end{abstract}

Keywords: WAC, baccalaureate curriculum, writing skills, communication skills, social work content

Effective social work practice requires sound writing and communication skills. Students entering social work programs, however, experience difficulties performing these skills at expected levels. It is imperative to identify, implement, and assess pedagogical techniques that will address these problems, thereby increasing student engagement and preparing them for successful performance of their professional responsibilities in the field. Writing Across the Curriculum (WAC) programs provide pedagogical techniques that are promising for improving writing and critical thinking skills among college students (Bean, 2001). Beginning in 2006, we developed a course that introduces students to social work values, ethics, and practice areas through the use of WAC techniques. The course continues to be taught every semester in multiple sections.

When the course was first developed, we asked students to complete a student selfreport survey to assess and describe their perceptions of the WAC course to determine its effectiveness and provide students with an opportunity to reflect on the development of their writing across the term. We used a self-report survey in this study because selfreport instruments have been described in the literature as usual methods of measuring learning strategies (Veenman, 2011) and collecting information about respondents' perceptions and attitudes about a particular subject (Schellings \& Van Hout-Wolters,

Naelys Luna, Ph.D., and E. Gail Horton, Ph.D., are Associate Professors in the School of Social Work, and Jeffrey R. Galin, Ph.D., is an Associate Professor and Director of the University Center for Excellence in Writing, all at Florida Atlantic University in Boca Raton, FL.

Copyright (C) 2014 Advances in Social Work Vol. 15 No. 2 (Fall 2014), 390-408 
2011; Veenman, 2011). In line with suggestions by multiple authors (Robinson \& Burton, 2009; Rubin \& Babbie, 2008; Schellings \& Van Hout-Wolters, 2011; Veenman, 2011) concerning the utility of self-report measures, the self-report format allowed us the flexibility to include multiple questions about the efficacy of the course with minimal loss of class time. In addition, since the students were already familiar with surveys utilizing Likert-like scales, the format produced minimal distress for them and, at the same time, made the project both cost- and energy-efficient for the researchers.

The results of the survey showed that nearly all respondents reported substantial to moderate improvement in writing and critical thinking skills. Students also reported that the process of writing facilitated acquisition of social work knowledge. These findings are highly encouraging for educators in our discipline, even though the high expectations for effective writing of this labor-intensive course challenged both students and faculty.

This paper presents survey findings on the perceived benefit of selected WAC strategies and techniques (substantive professor feedback, multiple drafts, peer review) on students' writing skills and social work knowledge acquisition. We have identified four themes within the survey for data reporting, including student perceptions of: 1) the general benefit of this course in improving their ability to write in the social work profession; 2) specific elements of composition, structure and style that they believed were improved (e.g. writing thesis statements, reorganizing and/or clarifying ideas, APA format, and proofreading for patterns of error) or needed further improvement after taking the WAC course (e.g. introduction, organization, argument); 3) specific WAC techniques that they believed were most effective in improving their writing skills; and 4) specific WAC techniques that facilitated their learning of social work content. The authors hypothesized that students would indicate substantial improvement in their writing skills after completion of the course and would indicate that WAC techniques facilitated knowledge acquisition of different content areas in social work. We offer a brief explanation of WAC principles, followed by a description of the Profession of Social Work WAC course and ways we examined its perceived benefits.

\section{Writing Across the Curriculum}

Since researchers and educators agree that social work students entering the field must be able to express their professional opinions and judgments in writing (Alter \& Adkins, 2006; Knight, 1997; Rompf, 1995; Simon \& Soven, 1990), it is important to examine pedagogical techniques that can ensure that students' writing skills are adequate for the work that they will be doing in the field. The WAC movement, which emerged in the 1970s, provides pedagogical techniques that faculty use to enhance the educational outcomes of students (McLeod \& Maimon, 2000). Proponents of the movement believed that writing could and should be used not only as a way to deliver some message that one wants to communicate, but also as a way to develop critical thinking that enhances the learning experience (Bean, 2001). Today, the main purposes of writing assignments based on WAC principles are "to use writing as a tool for learning rather than a test of that learning, to have writers explain concepts or ideas to themselves, to ask questions, to make connections, to speculate, to engage in critical thinking and problem solving" (McLeod \& Maimon, 2000, p. 579). Assignments should be developed so that they do not 
allow a single right answer, but rather require students to develop and utilize critical thinking skills in a discussion of multiple points of view (Bean, 2001). Thus, while students refine their writing skills, they also learn course concepts through the writing process itself.

\section{Description of the WAC Class}

The introductory WAC social work course that was developed in our school resulted from an emerging culture of support for writing in the School of Social Work. Over the course of six years, half of the social work faculty, including the Chair, participated in WAC seminars and made a commitment to integrate WAC principles throughout the curriculum. The WAC course developed by the authors is a three-credit, upper division class that is taught in multiple sections every semester. All undergraduate social work majors must pass it before they can enter practice courses and go into their field internship placements. The course combines traditional elements such as lectures, videos, in-class discussions, quizzes, midterm, and final exams with WAC writing assignments. These assignments require multiple drafts, substantive instructor feedback on drafts, and peer review. The class includes information on the various practice areas in social work, an introduction to basic social work values and ethics, and an explanation of the generalist intervention model.

Students are expected to complete two WAC writing assignments. The first is a short paper ( 5 to 6 pages including title page, abstract, and reference page). It requires them to compare and contrast the institutional (conservative), residual (liberal), and person-inenvironment perspectives concerning the provision of social welfare services as they apply to a case study. The second is a longer paper (10 to 12 pages including title page, abstract, and reference page). It requires students to read an article on the problems that can arise from engaging in dual relationships with clients and apply the concepts in that article to another case study. These two papers comprise $60 \%$ of students' final grade. Both assignments are considerably more complex than students expect when they enter the class, requiring them to write their papers using logical organization, acceptable professional language, and adequate APA formatting. We made a conscious choice to focus on academic writing rather than practice writing in this introductory course because we wanted students to learn how to read and think critically and express themselves clearly and coherently within the discipline. Students have opportunities to acquire field writing skills in later practice courses.

To support the students' efforts as they refine their drafts over the semester, the teachers provide instruction during every class on how to organize a paper, write adequate introductions and conclusions, and argue and support their ideas. A grading rubric that incorporates these ideas is supplied to the students during the first class that they use for writing their papers and self-evaluation. The rubric helps them see exactly what is expected of them as they write each section. It was developed by faculty members teaching the course to help them organize both their thinking and their writing. For example, the rubric specifies the writing elements that need to be included in the abstract, introduction, body, and conclusion of the paper (e.g., purpose, importance, thesis, and 
organizational statements in the introduction). In addition, it specifies the required APA format and grammar and punctuation rules (See Appendix for the rubric itself).

In addition, students use the rubric for a peer review process. First, a formal peerreview process is introduced by modeling it for students once in class; then students work in pairs outside of class, providing written feedback to each other using the grading rubric to ensure that they are addressing all of the elements of the paper. This process enables them to work with each other informally throughout the semester.

From this explanation of the class structure, readers may surmise that this course is challenging to both students and instructors. Students may have entered class with English as a second or third language or may never have been held to such high standards for writing performance. Students are frequently concerned about the complexity of the assignments, as well as the high expectations of their professors because they are encountering professional writing in the discipline of social work for the first time. Faculty also find the course challenging because they read and comment on multiple students' drafts, which require substantial time and attention. Approximately 50\% of class time is devoted to the content and organization of the two written assignments and to writing strategies and techniques. Early drafts may require up to 35 minutes per paper to evaluate, and there are up to 25 students in a class. The time instructors spend responding to revised drafts is nearly cut in half as a result of substantial revision. However, given the survey results and the authors' perceptions of their students' improvement, the authors concur with Light (2001) that "writing plays a pivotal role in the academic lives - and the academic success-of most students" (p. 55). More specifically, integrating writing - and specific writing strategies in particular-is instrumental to the professional development of social work students.

\section{Method}

\section{Design and Sample}

This descriptive cross-sectional study utilized a self-report survey developed to determine students' perceptions regarding the effectiveness of WAC strategies on their writing skills and social work content knowledge acquisition. The survey was developed during the Spring semester of 2008. Upon Institutional Review Board approval, the survey was administered at the end of each semester during Fall and Spring terms 20082010. Participants included students attending the WAC course on the date the survey was distributed. One hundred eighty-two students completed the survey.

\section{Students Survey Questionnaire}

The survey components were grouped into four categories: 1) the general benefit of the course in improving students' ability to write in the social work profession; 2) specific elements of composition, structure and style that students believed were improved or needed further improvement after taking the WAC course; 3) specific WAC techniques that students believed were most effective in improving their writing skills; and 4) specific WAC techniques that facilitated students' learning of social work content. 
Data were collected concerning demographic characteristics including respondents' age, gender, ethnicity, marital status, employment status, and place of birth (born in the United States).

General benefit of the course improving writing. Students used a 5-point Likerttype scale to indicate their overall impression regarding the perceived benefit of the WAC techniques employed in the course on their writing skills. For example, students were asked to rate the degree of writing improvement $(0=$ no improvement to $4=$ substantial improvement). They were also asked to rate what contribution the writing component made to their overall learning $(0=$ none at all to $4=$ substantially). Other questions included rating the extent to which students' critical thinking skills (i.e., knowledge, comprehension, application, analysis, synthesis, and evaluation) will transfer to future courses $(0=$ not at all to $4=$ substantially $)$, and the degree of confidence that they have improved their ability to write for the social work profession $(0=$ not confident at all to $4=$ very confident).

Specific elements of composition, structure, and style improving writing. Students used a 4-point Likert-type scale to indicate their perceptions regarding their improvement of specific writing elements in their writing skills. For example, students were asked to rate the degree to which the WAC revision process helped them to: 1) change focus or thesis; 2) reorganize substantially; 3) clarify ideas; 4) correct misinterpretations; 5) strengthen the relationships between ideas; 6) respond more effectively to the assignment; 7) proofread patterns of error; 8) correct citations; 9) provide additional evidence; and 10) reformat paper $(0=$ not at all to $3=$ to a substantial degree). A separate question asked students what writing skills needed further improvement after taking the WAC course (i.e., introduction, organization, transitions, arguments, analysis). A single question using a 5-point Likert-type scale $(0=$ no improvement to 4 = substantial improvement) assessed students' perceptions about learning APA format.

Specific WAC techniques improving writing. Students used a 4-point Likert-like scale to indicate their perceptions about the effectiveness of three WAC techniques on their writing skills. The first technique was the use of multiple drafts for each assignment. Respondents were asked to rate the degree of improvement from the first draft to the final draft $(0=$ no improvement to 3 = substantial improvement $)$. Students were also asked to identify the primary sources for the changes in their revisions (i.e. professor, writing center, classmates' feedback, response from outside readers).

The second technique involved the professors' feedback. Respondents were asked to rate their perceptions about how successful their assignment was before and after receiving feedback from their professor $(0=$ not very successful to $4=$ very successful $)$; students were also asked how many of the professors' comments they attempted to address $(0=$ none to $5=$ all $)$.

The last technique involved the peer review process in which students were asked to review and comment on a classmate's assignment using the grading rubric. Respondents were asked to rate the usefulness of classmates' comments on the revision process $(0=$ not useful at all to $4=$ very useful). 
Specific WAC techniques facilitating learning content. Respondents were asked five questions concerning to what extent the writing assignments in the class helped them learn about social work ethics and values, generalist practice, different areas of practice, and comprehending academic articles $(0=$ none at all to $4=$ substantially $)$.

\section{Data Analysis}

Quantitative analyses consisted of descriptive statistics and bivariate analyses using a Likert scale to determine the perceived benefits of WAC on writing skills. Frequencies, percentages, means, and standard deviations were reported. It is noteworthy that the number of students in some analyses (i.e. gender, ethnicity) do not correspond with the number of students in the total sample because not all students responded to all questions. Thus, $\mathrm{N}$ varies from 182 in several examples below.

\section{Results}

\section{Demographics of Participants}

There were 182 student respondents: $89 \%$ females $(n=159)$, and $11 \%$ males $(n=$ 20). Age ranged from 19 to 55 years old, with a mean of 27 . Twenty-five percent of the sample was born outside of the United States. Approximately 26\% $(n=48)$ of the respondents identified themselves as European American, 23.6\% $(n=43)$ as African American, $15.9 \%(n=29)$ as Latino, $16.5 \%(n=30)$ as Caribbean/West Indian, $3.3 \%(n$ $=6)$ as Native American, and $.5 \%(n=1)$ as Asian American. More than half of the sample $(n=99)$ reported being single, while $19.5 \%(n=34)$ indicated being legally married, $10.3 \%(n=18)$ cohabitating with partner, $8.6 \%(n=15)$ divorced, $3.4 \%(n=6)$ separated, and $0 \%$ were widowed. Approximately $13 \%(n=22)$ reported working more than 40 hours per week, $20.6 \%(n=36)$ reported working 40 hours per week, $41.7 \%(n=$ 73) worked fewer than 40 hours per week, 17.7\% (31) were unemployed, and 7.4\% $(n=$ 13) were homemakers or retired.

\section{General Benefit of the Course Improving Writing}

Thirty-six percent of the sample reported substantial improvement in writing, while $54 \%$ reported moderate improvement. A little over 13\% $(n=24)$ of students reported minimal improvement, and only $1.7 \%$ reported no improvement at all. Similarly, $38 \%(n$ $=68$ ) reported that they were very confident that this course improved their ability to write for the social work profession; 49\% $(n=88)$ reported being moderately confident about this skill; $11.2 \%$ reported being somewhat confident; and $1.7 \%(n=3)$ were not confident at all. Concerning critical thinking skills, approximately $62 \%$ of students reported that their efforts put into the writing assignments will help them substantially apply the knowledge learned in the course to other situations, break down information into component parts, and critically evaluate ideas and information. Figure 1 shows the results of questions concerning specific ways in which the course was beneficial. At least half of the respondents reported that this course will help them substantially remember, comprehend, and synthesize information while about $60 \%$ of the respondents indicated 
that the course would help them apply knowledge to future courses and analyze and evaluate information.

Figure 1. Students' Response to Survey Item: How Much Will The Efforts You Put Into Writing Assignments Help Demonstrate the Following Skills in the Future?

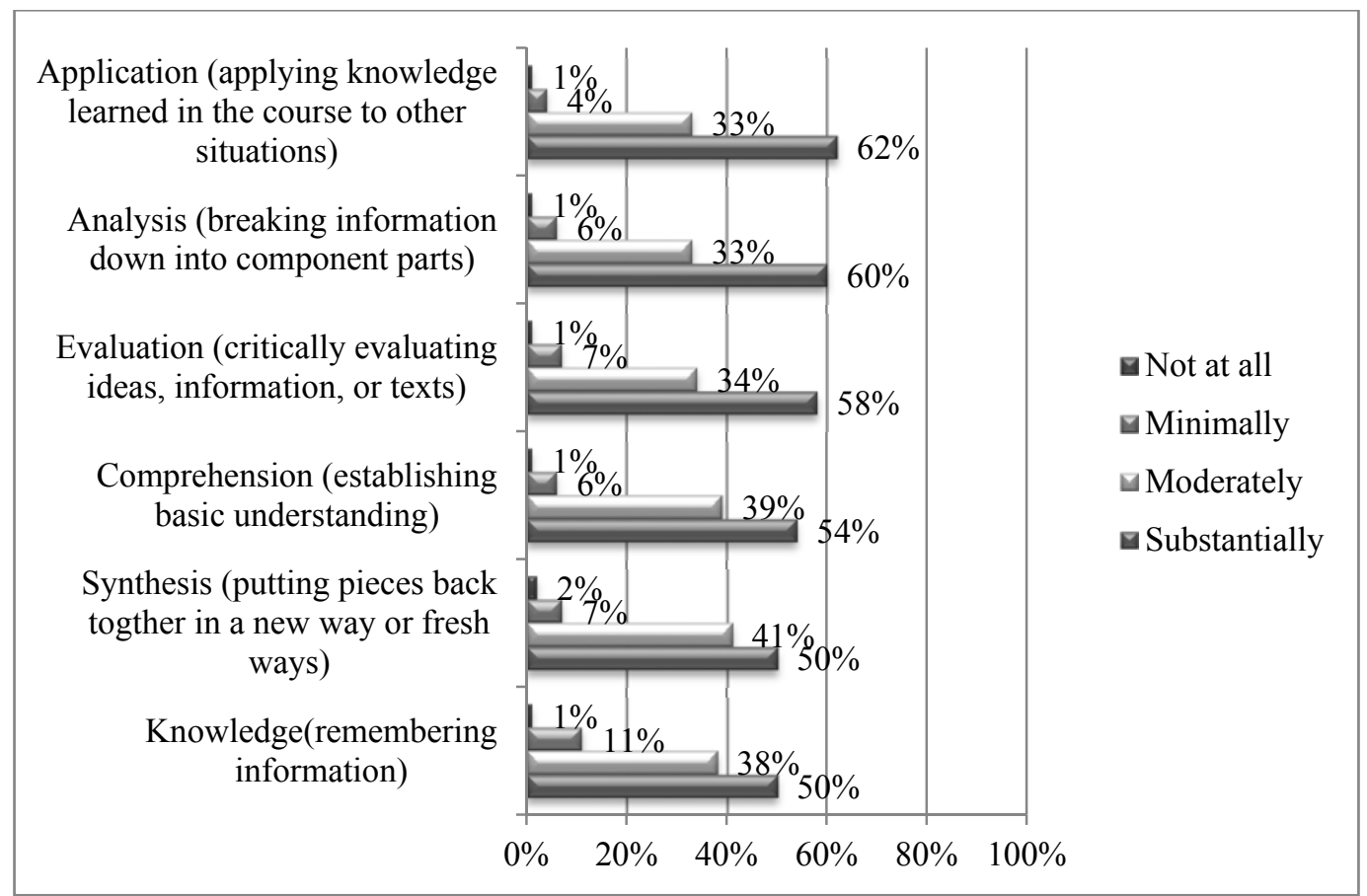

\section{Specific Elements of Composition, Structure and Style Improving Writing}

Results show that $62 \%(n=113)$ of students reported that their use of APA format substantially improved as a result of this course, 31\% $(n=57)$ reported a moderate improvement, $5 \%(n=10)$ reported minimal improvement, and only $1 \%(n=2)$ reported no improvement. Figures 2 and 3 present the results of questions concerning skills students felt still need improvement after taking the WAC course. Approximately half ( $n$ $=84)$ reported that they need to improve the use of APA style; $43 \%(n=78)$ reported grammar and punctuation; 37\% $(n=68)$ indicated the development of a strong thesis statement; $29 \%(n=52)$ organization; $26 \%(n=47)$ arguments; $22 \%(n=40)$ use of paraphrase and direct quotation; and $20 \%(n=37)$ conclusions. 
Figure 2. Students’ Response to Survey Item: I Still Think I Need To Improve in My Writing

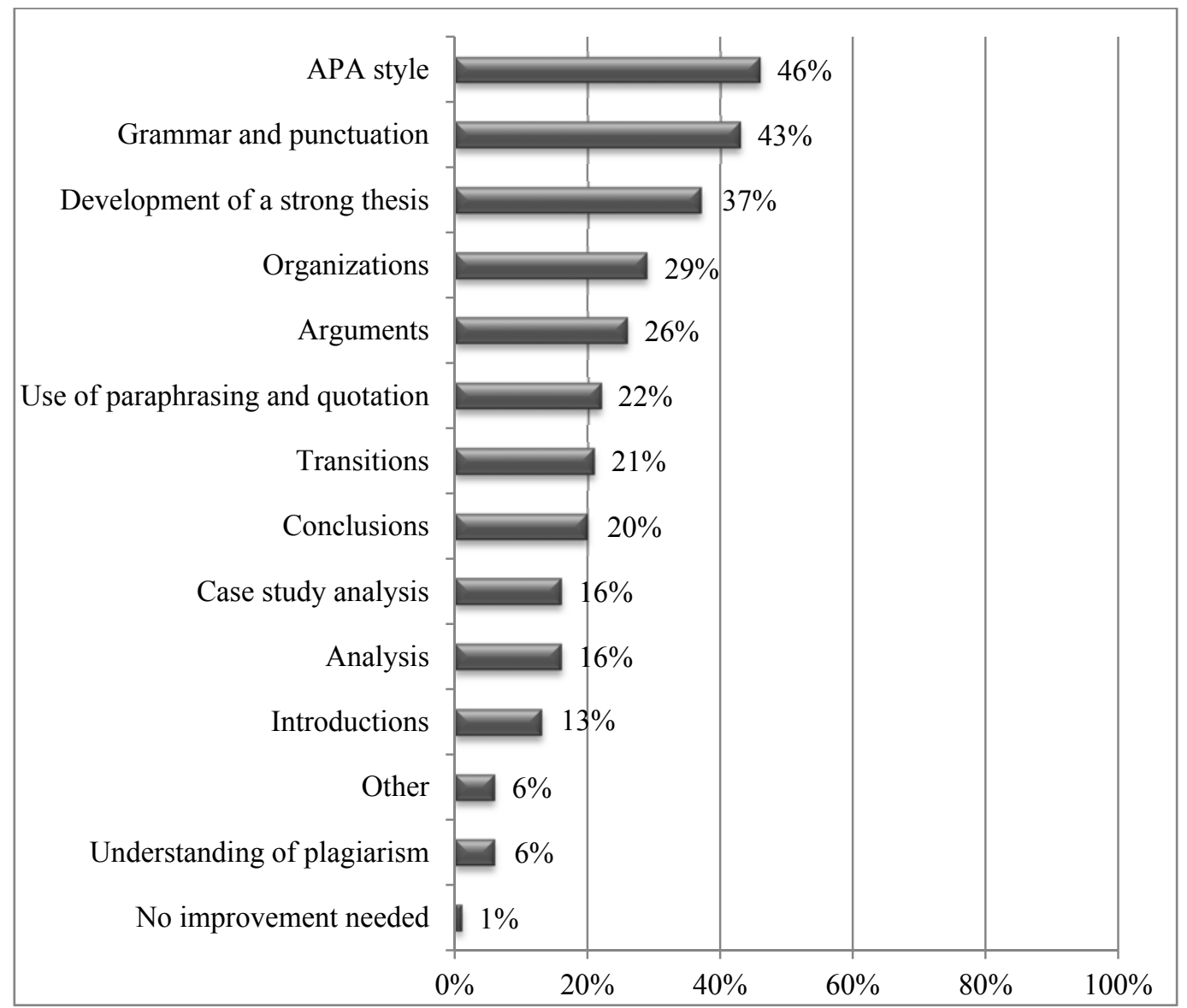

Students also reported that they wished they could improve their writing in the following ways: $35 \%(n=63)$ organize thoughts; $27 \%(n=49)$ edit; $25 \%(n=45)$ think critically; $24 \%(n=43)$ communicate; $19 \%(n=34)$ paraphrase; $11 \%(n=20)$ summarize and evaluate; and $10 \%(n=18)$ persuade. 
Figure 3. Students' Response to Survey Item: I Wish I Could My Writing More Effectively in

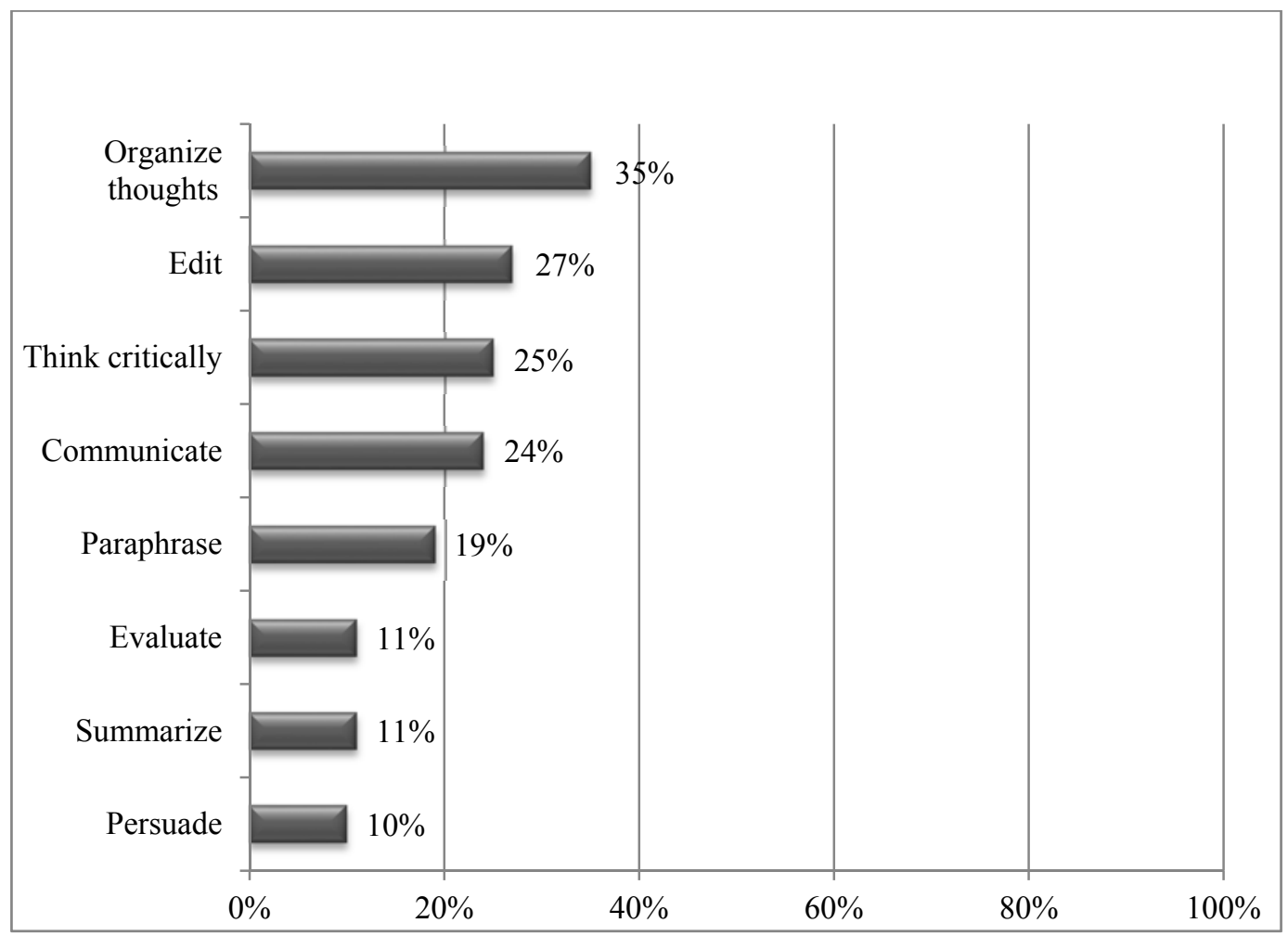

Figure 4 presents the results of the analyses concerning the writing elements students used more frequently as they revised their work. Students reported that the following WAC writing elements were used to a substantial degree during the revision process: 1) $61 \%(n=104)$ proofread for patterns of error in grammar, punctuation, spelling, and word choice; 2) 58\% $(n=100)$ corrected misinterpretations; 3$) 56 \%(n=95)$ responded more effectively to the assignment; 4) 55\% $(n=95)$ clarified ideas; 5) $52 \%(n=90)$ corrected citations and references; 6) 50\% $(n=85)$ clarified sentences; 7) 40\% $(n=68)$ strengthened relationships between ideas; 8) and 9) 38\% $(n=65)$ provided additional evidence and reorganized the assignment substantially; 10) $37 \%(n=64)$ reformatted the assignment; and 11) 29\% $(n=50)$ changed the focus or thesis of the assignment. 
Figure 4. Students' Response to Survey Item: Rate How Much You Used Each of the Following Revision Elements.

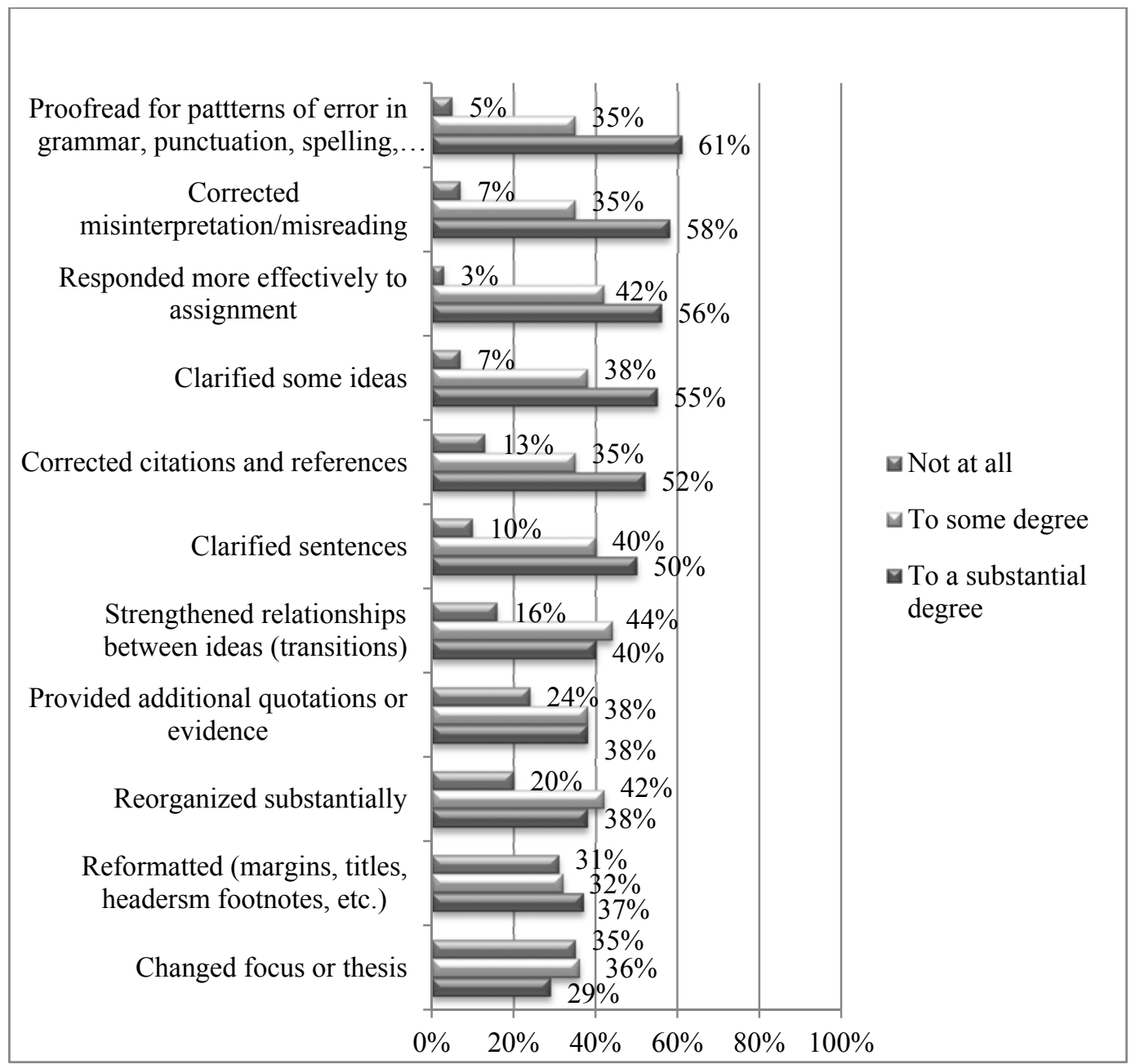

\section{Specific WAC Techniques Improving Writing}

Forty-seven percent $(n=79)$ of students reported that the multiple revisions of the writing assignments helped them improve their writing substantially from the first draft to the final draft, $42 \%(n=71)$ reported moderate improvement, and $4 \%(n=7)$ of students felt that they had fulfilled the assignment very successfully before the professors' feedback. In comparison, 19\% $(n=33)$ of students felt that after receiving professor feedback, they had fulfilled the assignment very successfully. Thirty-four percent $(n=$ 62) felt that they had been successful in fulfilling the assignment before professor's feedback, and $51 \%(n=92)$ reported feeling that they had been somewhat successful. In comparison, $33 \%(n=58)$ and $29 \%(n=51)$ reported feeling successful or somewhat successful, respectively, after the feedback. Seventy-seven percent $(n=135)$ reported 
attempting to respond to all the professor's comments, while $17 \%(n=30)$ responded to most, $5 \%(n=8)$ responded to some, and 1\% $(n=2)$ responded to none. Eighty-nine percent $(n=162)$ also reported that the primary source for the changes made on their papers came from the professors' comments. Twenty-six percent $(n=32)$ and $35 \%(n=$ 44) of students reported the peer review process to be very useful or somewhat useful respectively, 26\% $(n=33)$ reported it to be minimally useful, and 13\% $(n=16)$ not useful at all. Thirty-three percent $(n=60)$ of students reported that they used their classmates' responses during the peer review process as a primary source for making revisions of their assignments.

\section{Specific WAC Techniques Facilitating Learning Content}

Forty-one percent $(n=73)$ of students indicated that this WAC course, compared to non-WAC courses, substantially contributed to the overall learning of course material, $44 \%(n=80)$ reported moderate contribution, $13 \%(n=24)$ reported minimal, and $2 \%(n$ $=3)$ reported none at all. In addition, $73 \%(n=132)$ of students reported that the writing assignments in the course substantially helped them to learn about social work ethics and values, $51 \%(n=91)$ about generalist practice, and $42 \%(n=75)$ about different areas in social work practice (e.g., criminal justice, schools, children and families) (See Table 1). Forty-seven percent $(n=85)$ of students indicated feeling very confident, $41 \%(n=75)$ moderately confident, $11 \%(n=19)$ somewhat confident, and $1 \%(n=2)$ not confident at all about comprehending academic articles after taking this class.

Table 1. Extent to Which Writing Assignments Helped Student to Learn Different Social Work Content Areas

\begin{tabular}{lcccccccc}
\hline & \multicolumn{3}{c}{ Substantial } & \multicolumn{3}{c}{ Moderate } & \multicolumn{3}{c}{ Minimal } & \multicolumn{2}{c}{ None at all } \\
Social Work Content Areas & $n$ & $\%$ & $N$ & $\%$ & $n$ & $\%$ & $n$ & $\%$ \\
\hline Ethics and values & 132 & 73 & 39 & 22 & 10 & 6 & 0 & 0 \\
Generalist practice & 91 & 51 & 73 & 41 & 15 & 8 & 0 & 0 \\
$\begin{array}{l}\text { Different areas of practice (i.e., } \\
\text { children and families, school, } \\
\text { etc.) }\end{array}$ & 75 & 42 & 71 & 39 & 26 & 14 & 8 & 5 \\
\hline
\end{tabular}

\section{Discussion}

The purpose of this paper was to present survey findings on the perceived benefit of WAC strategies and techniques on students' writing skills and the acquisition of social work knowledge. Effective social work practice requires sound writing and communication skills. Previous studies have indicated concerns among social work educators resulting from their students' academic difficulties. Furthermore, the Council on Social Work Education has changed accreditation standards to emphasize educational outcomes demonstrating students' competencies for the practice of social work (Council on Social Work Education, 2008). Thus, it is crucial to identify, implement, and assess 
pedagogical strategies that improve the skills of future practitioners. The findings of this study are promising because participants reported that the WAC strategies and techniques employed in the course were effective in improving their ability to write professionally and to think critically about important social work concepts.

In regard to the perceived general benefit of the WAC course, $36 \%$ of 172 participants reported substantial improvement in their writing skills, and an additional $54 \%$ indicated moderate improvement. Thirty-eight percent of the sample reported being very confident that this course helped them to improve their ability to write for the social work profession. Sixty percent of the sample reported that the skills they learned, developed, or improved in this course will transfer to future courses.

The three WAC techniques examined in this study appeared to be effective. Approximately half of the sample reported that the multiple revision process helped them substantially to improve their assignment. Eighty-nine percent of the respondents indicated that professors' feedback was the primary source for revisions they made in their writing. In addition, more than half of the sample reported that the peer-review process was very useful or somewhat useful. Respondents identified multiple writing skills that were improved as a result of the WAC course. Some of these skills included correcting patterns of errors in grammar, punctuation, spelling, word choice, responding more effectively to assignments, clarifying ideas, reorganizing the assignment, and providing additional evidence to support claims. Furthermore, the WAC course appeared to be effective in helping students learn the APA format and social work content (e.g., sixty-two percent of the sample reported that their use of APA format substantially improved).

The course writing assignments were fundamental in helping students learn social work content. Seventy-three percent of the respondents indicated that the writing assignments substantially helped them learn about social work ethics and values, fiftyone percent about generalist practice, and forty-two percent about different areas in social work practice including criminal justice, schools, and children and families. These results confirm Light's (2001) general claims for undergraduate perceptions of student writing and their engagement in course material. He reports that there is a stronger relationship between the amount of student writing in a course and student engagement than with any other factor, including impressions of faculty, whether the course was required or not, or whether the course fulfilled a requirement in a major. Light found that courses with more than twenty pages of "final draft writing" take about twice as much time as courses with no formal writing assignments (p. 56). Students also reported that the greater amount of writing required, the greater they found the intellectual challenge of the course. Finally, they reported that the impact of writing assignments on their engagement was dramatic.

\section{Implications for Teaching and Curriculum Development}

The results of this study suggest that the school's commitment to writing is justified. The integration of WAC into the social work curriculum involved extensive faculty training, including a three-day intensive WAC seminar, several months of planning and designing the course's written assignments, and development of writing assessment tools. 
In addition, the authors received a WAC grant to develop and produce a DVD for orienting students to the importance of writing in the field of social work. The school also provided WAC workshops for adjunct faculty teaching non-WAC courses to familiarize them with the school's writing expectations and to help them introduce writing strategies into all of their courses. These efforts have resulted in social work students earning the second highest scores in a university wide assessment of writing assignments across eight different departments. Figure 5 shows the results of a stratified random sample of student papers submitted from 10 to 15 WAC classes a semester across the university. Each paper was rated using a 12- trait rubric on a four point scale, with 4 representing highest ability, and 1 representing least ability. Social Work and Nursing were the only departments whose scores were rated statistically significantly higher than the other departments. Given the difficulty and high expectations of the course, this outcome is particularly noteworthy.

Figure 5. Results from an Assessment of WAC Programs across the University

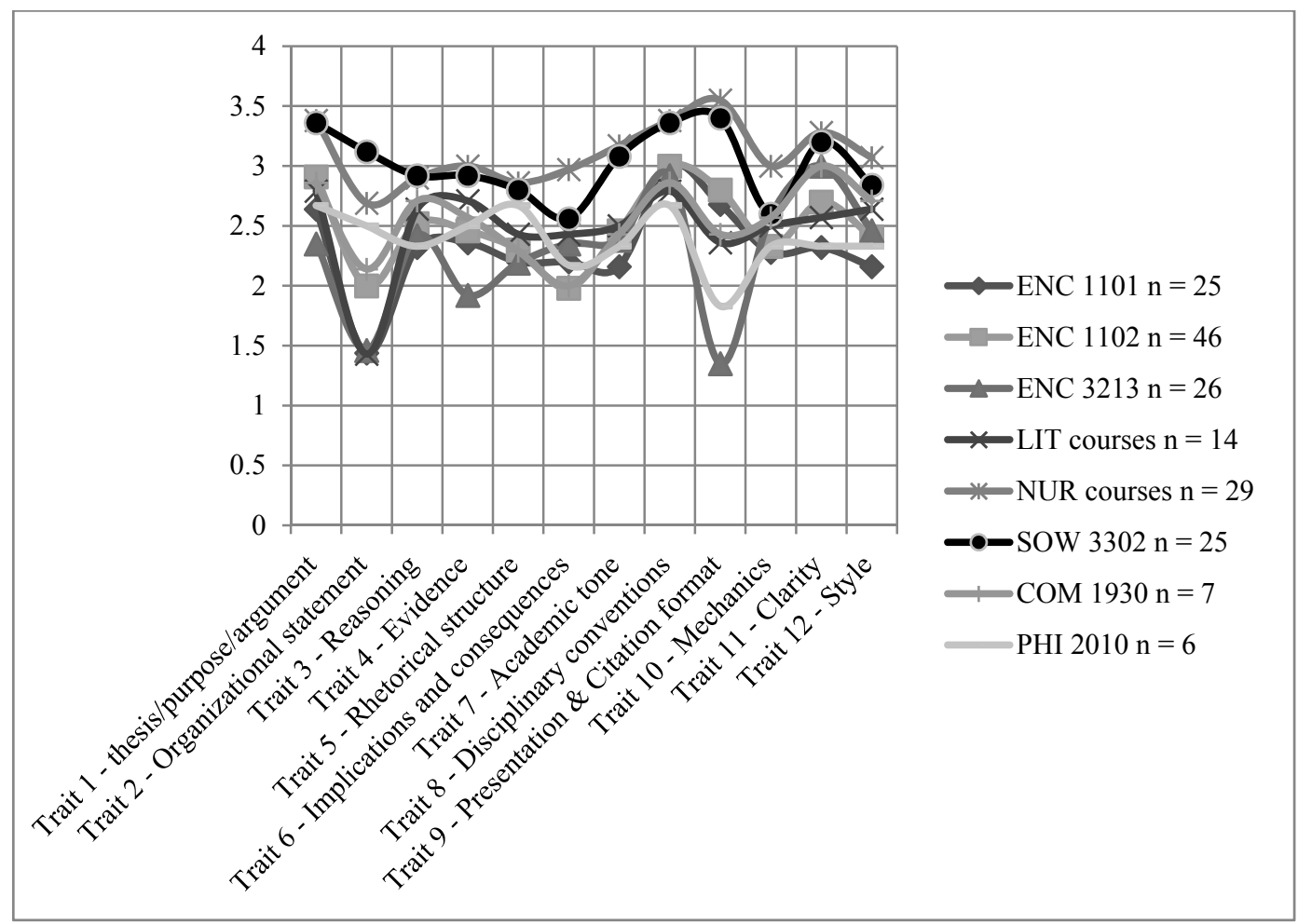

There are three significant factors that may account for the positive outcomes of this course: 1) the commitment of the core faculty members who initiated, developed, and continue to teach the course; 2) the ongoing support of the school's Director; and 3) the collaboration with the university WAC program. The authors believe that all of these factors were essential to the success and sustainability of this curriculum. 


\section{Commitment of Core Faculty}

The curriculum development and the success of this course have been dependent upon the commitment of the faculty who designed and now teach sections of the course. For this writing-intensive course, faculty members must spend significant amounts of time responding to drafts and must devote class time and office hours to helping students improve their writing. In addition, faculty members meet at least two to three times a semester to norm and reevaluate teaching strategies. As a result of these ongoing meetings, we have developed on-line learning modules for basic writing and APA formatting skills to provide additional support for students. Furthermore, one faculty member leads half-day workshops for adjunct instructors each semester to infuse WAC techniques across other courses in our curriculum. This ongoing commitment ensures quality and consistency of the curriculum, allowing the School of Social Work to maintain high writing standards.

The increased writing standards have impacted students' evaluation of teachers' performance, particularly when the new course was implemented. Most incoming social work students do not anticipate a strong emphasis on writing nor the significance of writing in the field. Initially faculty members experienced resistance from students because of the writing demands of the course. However, over time the culture of the program has changed, and students now tend to know in advance that writing is a central component of the social work curriculum. As the teaching of the course has been refined and faculty confidence has increased, the quality of students' writing has improved as demonstrated by students' perceptions of their own writing. In addition, results from a recent university-wide WAC assessment study indicated that social work students scored second highest in terms of the quality of writing among students from seven other disciplines. Other social work programs that implement a similar emphasis on writing should, however, expect some level of resistance from students at first because of the higher writing expectations and demands that the new course requires. These attitudes will likely improve as the new culture emerges.

\section{Director of the School of Social Work Support}

In addition to the commitment of the core faculty, the support of the Director was essential to the successful development and implementation of this course. The Director participated in one of the first WAC seminars and carried her enthusiasm back to the faculty. Recognizing the difficulties in learning how to teach this course, she was available to discuss faculty concerns about students' performance during the semester and their evaluation of it at the end. She recognized that students did not expect writing to be such a fundamental component of the course. Therefore, they tended to give lower teacher evaluation scores to the instructors for the first few terms it was taught, which is a salient factor given the instructors' tenure-seeking status. When the faculty submitted their tenure portfolios, she defended the lower student evaluations of the course while highlighting the work and commitment involved in teaching the course. In an effort to validate the instructors' commitment and effort, she has ensured that the faculty accomplishments have received public recognition at the school, college, and university levels. For schools considering implementation of a writing program such as the one 
presented here, it should be noted that without the support of administration, it would be very difficult to initiate and maintain the required time and effort in the face of the challenges presented by a class such as this one.

\section{Collaboration with the Director of the UCEW}

Collaboration with the Director of the University Center for Excellence in Writing, who also serves as the Director of the WAC program for the university, was also essential to the success of the course. He has been an active partner throughout this process, leading the workshops that faculty have attended and substantially contributing to the course development. He has met regularly with social work faculty over the course of four years, provided feedback on strategies for grading papers, offered recommendations about the development of the course syllabus, and helped develop assignments and WAC student surveys. In addition, he encouraged social work faculty to submit a grant, which was accepted, to develop a promotional DVD on the importance of writing. Furthermore, he has collaborated as a partner in writing research manuscripts and presenting them at national conferences. Social work programs that develop a writing program similar to the one presented here should consider carefully the need for collaboration with a WAC Director or other departments within the university. These collaborations provide essential support, credibility, and incentive to sustain such initiatives.

\section{Limitations}

Several methodological issues and limitations related to the design of the study and the use of self-report must be considered when interpreting the findings. There were no baseline measures before the WAC course was implemented. Therefore, it would be difficult to determine if improvements in students' writing skills resulted from the WAC course. However, there were no substantial curriculum changes in the school of social work during the data collection period. While we could have employed other methods for examining the perceived benefit of the course, we used students' perceptions only. Although we developed a survey to examine faculty perceptions of students' writing and critical thinking, the response rate was insufficient for data analysis. We had no resources to support independent reviews of students' drafts by external reviewers outside of the discipline. In addition, this study involves a cross-sectional design, which does not provide information about the long-term effect of WAC techniques on students' writing skills.

One concern involving self-report is that students exhibit problems assessing their information skills and accurately recollecting what they have done (Schellings \& Van Hout-Wolters, 2011; Schilling \& Applegate, 2007). However, in this study we administered the surveys during the last weeks of the semesters when the skills and knowledge we inquired about were being practiced in the classrooms and instructors were giving extensive feedback to the students about those areas. Thus, our students had a clear notion and awareness as to the content of the questions included on the survey.

Despite these limitations, the current study has several strengths. This study is the first of its kind to examine social work students' perception of the effectiveness of WAC 
techniques. In addition, the sample size was relatively large $(n=182)$, and it included students attending different sections of the course and different semesters. Due to the scarcity of research with respect to pedagogical techniques beneficial to social work students, this study fills an important gap in the literature.

Future research should continue to examine the perceived benefit of WAC techniques on educational outcomes and the long term sustainability of such programs. It is crucial to improve the communication and writing skills of social work students and better prepare them to be successful professionals in the field. Furthermore, faculty members' perceptions of students' improvement and baseline data on students' outcomes should be included in future studies to establish validity of perceived benefit of WAC techniques. Future studies should also have a longitudinal design to examine the long-term effect of the writing improvement and knowledge acquisition. Lastly, this paper was a descriptive study intended to present the multiple factors related to the perceived helpfulness of WAC techniques. A future publication will include findings examining the impact of demographic variables on the perceived benefits of WAC.

\section{Conclusion}

While most mental health practitioners, educators, and other professionals recognize that writing skills are essential for effective social work practice, few social work programs have published information concerning the implementation of curricula that address these needs. The primary purpose of this paper was to present survey findings on the perceived benefit of the WAC strategies and techniques on students' writing skills and social work knowledge acquisition. Findings indicated that students perceived substantial improvement in their writing skills after the completion of this course. In addition, WAC techniques facilitated knowledge acquisition from different content areas in social work. These results support the implementation of WAC into social work curricula and suggest a potential model that other programs might use to better prepare future practitioners in the field. The sustainability of our program, and any that follow, requires: 1) departmental support and recognition by both faculty and administration of the importance of writing within the social work curriculum; 2) continuous commitment of the faculty teaching the course; and 3) collaboration with university writing programs.

\section{References}

Alter, C., \& Adkins, C. (2006). Assessing student writing proficiency in graduate schools of social work. Journal of Social Work Education, 42(2), 337-354.

Bean, J. C. (2001). Engaging ideas: The professor's guide to integrating writing, critical thinking, and active learning in the classroom. San Francisco, CA: Jossey-Bass.

Council on Social Work Education. (2008). Educational policy and accreditation standards. Retrieved from http://www.cswe.org/Accreditation/Handbook.aspx

Knight, C. (1997). The use and evaluation of a writing lab for undergraduate social work students. Journal of Baccalaureate Social Work, 2, 103-113. 
Light, R. (2001). Making the most of college: Students speak their minds. Boston, MA: Harvard University Press.

McLeod, S., \& Maimon, E. (2000). Clearing the air: WAC myths and realities. College English, 62(5), 573-583.

Robinson, T. A., \& Burton, V. T. (2009). The writer's personal profile: Student self assessment and goal setting at start of term. Across the Disciplines, 6. Retrieved from http://wac.colostate.edu/atd/assessment/robinson_burton.cfm

Rompf, E. L. (1995). Student writing in social work: An aggravation or an opportunity for social work educators? Journal of Teaching in Social Work, 12(1/2), 125-138.

Rubin, A., \& Babbie, E. R. (2008). Research methods for social work (6 ${ }^{\text {th }}$ ed.). Pacific Grove, CA: Brooks/Cole.

Schellings, G., \& Van Hout-Wolters, B. (2011). Measuring strategy use with self-report instruments: Theoretical and empirical considerations. Metacognition Learning, 6, 8390.

Schilling, K., \& Applegate, R. (2007). Evaluating library instruction: Measures for assessing educational quality and impact. Paper presented at the ACRL $13^{\text {th }}$ National Conference, Baltimore, Maryland. Retrieved from http://0-

www.ala.org.catalog.wblib.org/acrl/sites/ala.org.acrl/files/content/conferences/confsa ndpreconfs/national/baltimore/papers/206.pdf

Simon, B. L., \& Soven, M. (1990). The teaching of writing in social work education: A pressing priority for the 1990s. Journal of Teaching in Social Work, 3(2), 47-63.

Veenman, M. V. J. (2011). Learning to self-monitor and self-regulate. In R. Mayer \& P. Alexander (Eds.), Handbook of research on learning and instruction (pp. 197-218). New York, NY: Routledge.

\section{Author note}

Address correspondence to: Naelys Luna, School of Social Work, Florida Atlantic University, 777 Glades Road, SO314, Boca Raton, FL, 33431. Email: ndiaz10@,fau.edu 
Appendix

\section{Grading Rubric}

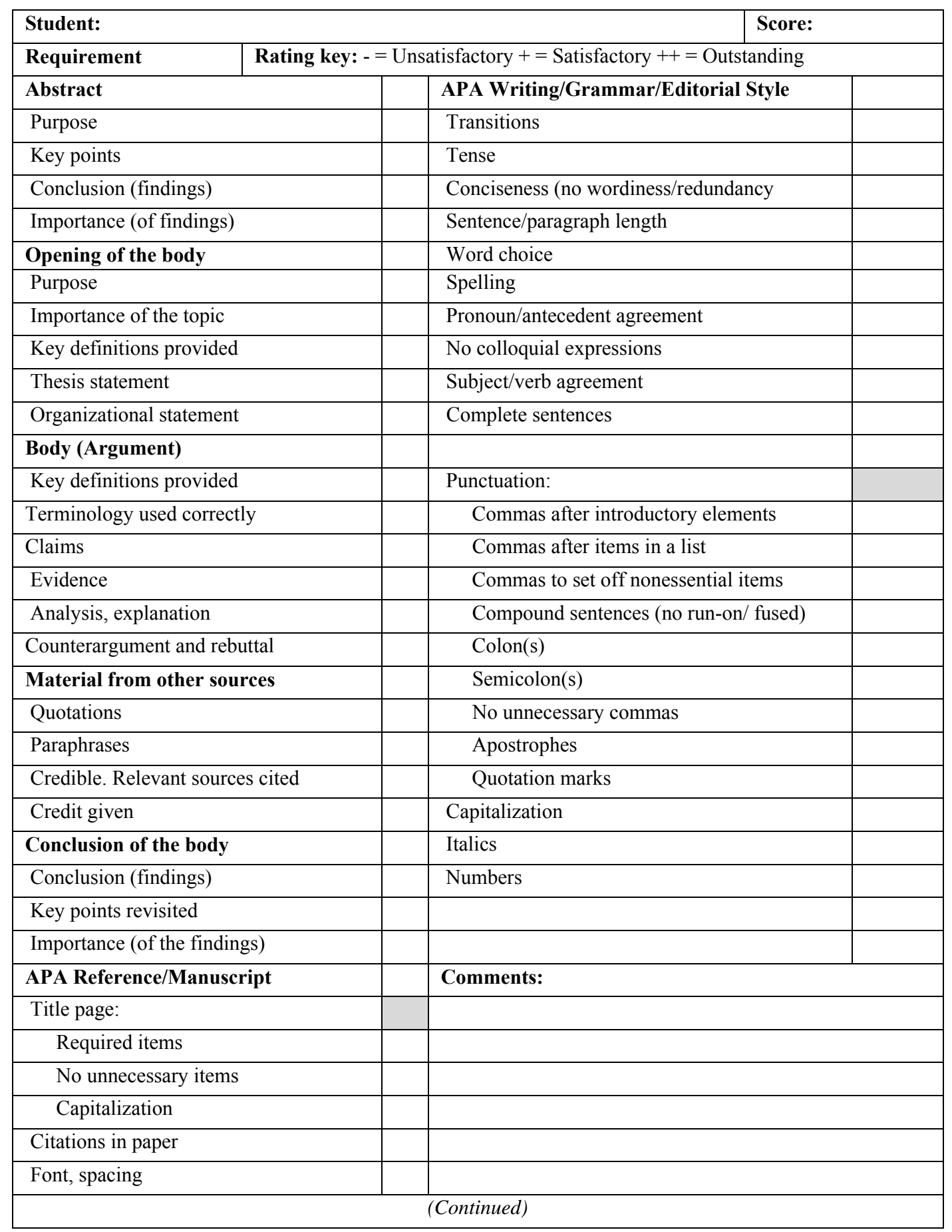




\begin{tabular}{|l|l|l|}
\hline Indentation, margins & & \\
\hline Headings & & \\
\hline Reference page: & & \\
\hline Required items & & \\
\hline Capitalization & & \\
\hline Italics & & \\
\hline Alphabetization & & \\
\hline Page headers & & \\
\hline
\end{tabular}

